Europe's Journal of Psychology 2/2010, pp. 1-6

www.ejop.org

\title{
The Message of the Medium: \\ Distributing academic knowledge in the Digital Age
}

\author{
By Alex Gillespie \\ Department of Psychology, University of Stirling
}

Technology supporting the production of academic knowledge has come a long way and Europe's Journal of Psychology is at the forefront of a new phase in the dissemination and discussion of knowledge. Before the advent of writing, knowledge was spread by word of mouth often through poems to aid memory. Writing was obviously a breakthrough, but it has taken millennia to refine. Unwieldy scrolls became books with pages allowing easy access to each part of the text. The printing press, which made the reproduction of information easy and cheap, was obviously a major breakthrough. But many micro-inventions were required for this medium to mature. Introducing spaces between words greatly increased readability, as did paragraph breaks. Page numbers, chapters, chapter titles, and indexes improved accessibility (Chartier, 1995). Journal articles developed their own conventions of titles, abstracts, keywords, and predictable organisation. The technologies of The Age of Print are not only found within printed books and journal articles. Institutions grew up around printed material supporting the creation, distribution, archiving, and searching of the material. In libraries across the world, books were catalogued and shelved, journal articles were abstracted, keywords parsed, and massive index systems compiled.

Although The Age of Print can be characterised as a collection of relatively mundane technologies, the impact of the increased accessibility of knowledge was far from mundane. The circulation of perfectly reproduced books and articles widely and relatively cheaply was central to the Renaissance (Burke, 2000). Without standardised and widely disseminated narratives and images of nationhood it is questionable whether national identities would have become as potent as they are (Anderson, 1993). And the endless reproduction of a few dozen characters into a huge number of words and an infinite realm of meaning has been argued to provide 
a basis for the regimentation and mass production mentality which characterised modernism (Ong, 1982).

The Age of Print has ended. We have crossed the threshold into The Digital Age. In the past few decades our relationship to information has changed fundamentally. The book, the page, the index, and even the library are anachronistic relics of a previous era. During the twentieth century many predictions were made about the future. It was thought that communities would be established on the moon, factories would produce so much that people could work less, and vehicles would be replaced by personal aircraft powered by nuclear generators no bigger than a microwave oven. But these were dreams of a more mechanical age. Future historians, I suspect, will look back on our era and see, above all else, the digitisation of information.

The Digital Age is, like the Age of Print, basically a collection of relatively mundane technologies. Computers, network hardware, network software, hyperlinks, embedded multimedia, social networking media, online forums, and security systems are all central. But perhaps the most important single technology is the search engine (Battelle, 2006). Aggregation of digital information would be relatively useless if it was still catalogued in the same way as the libraries of the twentieth century. Indeed, Yahoo! began by trying to produce an index of the World Wide Web, but the index became far too unwieldy to navigate. Introducing word search was important, but organising the output of a search of several billion items in rank order of quality was the real breakthrough. The simple insight that the quality of a web page can be inferred from the number of websites linking to that web page is the mundane idea on which Google was built.

In the not too distant future it will seem quaint that journal articles and books within the digital realm are essentially scanned paper copies, which is to say, they duplicate the paper 'originals.' Digitised documents, complete with pages and page numbers, are transitional. Once academic publishing embraces the digital medium we can expect reviewers' comments to appear alongside the target article, discussion boards attached to articles, and new forms of metrics based on reading, commenting, rating, and linking data.

It would be overly simplistic to characterise The Digital Age as the digitization of that which was previously printed. We are not dealing with a new distribution channel, which can be incorporated into existing infrastructure. Digitisation is a paradigm shift, which will make many of the previous innovations redundant, and which will open 
up possibilities that we cannot yet imagine. McLuhan (1964) argued that one cannot separate the medium from the message. Each medium, whether spoken, written, or digital, has its own logic which unfolds in a world of practice creating new and unforeseen affordances and constraints. What a medium enables and constrains is the message of the medium. The printing of what was previously written did not simply make communication more efficient, it transformed information, society, and the way people think and act. The key question is: What is the message of the digital medium?

The message of the digital medium is that the cost of reproducing information has become negligible. This most fundamental aspect of the digital revolution is not a mundane technology, it is an inherent aspect of the medium - it cannot be put aside or ignored, it is the logic of digitisation itself. With centralised storage, and local access points combined with powerful search, the entirety of the world's digitised knowledge and cultural output is, in principle, accessible to everyone. If knowledge is power, then this surely has the potential to be a quantum leap forward in human empowerment. The printing presses made knowledge more accessible. Digitisation has the potential to take this accessibility to its limit. Given the social and psychological consequences of the printing press it is surely an understatement to say that the coming decades and centuries, in which the logic of The Digital Age unfolds, will be exciting.

The digital revolution has the potential to revolutionise academia. But as with any revolution, there are winners and losers, and thus a complex power struggle is unfolding (Lessig, 2004). The fact is that we are now, collectively, expending resources on limiting the accessibility of academic outputs. Most academic articles are stored in archives, which require expensive subscriptions to access. Downloaded articles often include technology which causes them to expire after a set amount of time and/or prevents their further circulation beyond the original receiver. The present system, by trying to inhibit circulation and duplication, is going against the message of the medium.

The present phase of the digital revolution in academia is based on restricting access to knowledge. In the present system, tax payers pay for research twice. Usually they provide the funding for research in the first place, and then they provide the funds for institutions to buy access to that same research. And despite paying for researchers to both create and access research, these tax payers do not have access to this research. Restricting access to research means that the public do not have access to information which might help them to make decisions about health, technology, social, legal, or other issues. Second, it means that when this public goes 
to university, they often don't have access to many of the key articles and books they are meant to be studying. Third, it means that many researchers are either denied access to research by the limitations of departmental budgets or spend a lot of time logging into password protected archives. Moreover, it means that the public and academics in developing countries, which are being supported by large development grants, are denied the knowledge resources which would be invaluable in enabling their own development.

How we have arrived at the present system is understandable. In the Age of Print, publishing houses unwittingly based their income on the physicality of printed material. By controlling the means of printing, they were able to levy their entirely justifiable fee with the sale of each production. But now the means of production have become ubiquitous, and thus artificial mechanisms have had to be introduced to protect the publishers' income through restricting access. But the unintended consequence of protecting publishers' income, in this particular way, is to fight an uphill battle to neuter the core message of the digital revolution.

Whoever produces, proofreads, compiles, organises, and hosts online media should receive financial payment. But there are many ways in which this payment can be provided. Currently we are applying zero-sum economics to what has become a non-zero-sum resource (Whitworth \& Friedman, 2009). We need to update our economic model to ensure that the message of the digital medium is given full expression. Some have suggested that the funders of academic research should pay for the digital production and online open access hosting of the resultant information, thus ensuring the broadest possible impact of the research. Gadd, Oppenheim and Probets (2003) suggest that universities should re-assert ownership over academic outputs and host these outputs themselves. For universities to host online peer reviewed open access archives of the research conducted within the university would arguably cost less than the cost of the library's current subscription to journals. If all universities did this it would, over time, make the majority of the world's academic knowledge free to everyone as a collective resource. It is impossible to know how the dissemination of academic knowledge will change in the coming years, but we can be certain that it will change.

Maybe the future is here, in journals such as Europe's Journal of Psychology (Ispas, 2006). One salient aspect of the digital revolution in academia is an explosion of online open access journals. The Directory of Open Access Journals, as of May 2010, lists 5023 open access journals. Each of these journals is free, with full text access, and quality controlled. Unfortunately, Psychology has poor representation. There are 363 
journals in Medicine and 340 journals in Education, but only 117 journals in Psychology. Nevertheless, examining these 117 journals in more detail provides us with important clues as to the future of academic publishing: 91 of the 117 open access Psychology Journals are published outside of North America, and the majority are not in English. Clearly there are tectonic shifts occurring. Thompson ISI, which hosts the main established database of natural and social science journals records few open access journals and explicitly prefers journals which publish in English. Are we witnessing the emergence of an alternative academic realm, which is outside the hegemony of the established journals?

These new open access online journals, which encourage circulation and duplication, are an expression of the message of The Digital Age. The future rise of these open access journals will be inversely proportional to the extent to which the established journals are exclusionary based on cost, content, or language. We are living in revolutionary times. The digitisation of knowledge, now means that it is often more expensive to stop the distribution of knowledge than to allow it. In the past, increases in the accessibility of knowledge have had profound social and psychological effects. What the new phase of accessibility made possible in the Digital Age will lead to is unknown. But what is certain is that the foundations of the future of academic knowledge dissemination are being built not just now, but in online, free access, peer reviewed journals like Europe's Journal of Psychology.

\section{References:}

Anderson, B. (1993). Imagined communities: Reflections on the origin and spread of nationalism. London: Verso.

Battelle, J. (2006). The Search: How Google and Its Rivals Rewrote the Rules of Business and Transformed Our Culture. New York: Portfolio.

Burke, P. (2000). A social history of knowledge: From Gutenberg to Diderot. Cambridge: Polity.

Gadd, E., Oppenheim, C., \& Probets, S. (2003). RoMEO studies 1: The impact of copyright ownership on academic author self. Journal of Documentation, 59(3), 243 - 277.

Ispas, D. (2006). Academic publishing: The future is here. Europe's' Journal of Psychology, May $22^{\text {nd }}, 2006$. 
Lessig, L. (2004). Free culture: The nature and future of creativity. New York: Penguin Books.

McLuhan, M. (1964). Understanding media: The extensions of man. London: Ark.

Ong, W. J. (1982). Orality \& literacy: The technologizing of the word. London: Routledge.

Roger Chartier, 1995. Forms and meanings: Texts, performances, and audiences from codex to computer. Philadelphia: University of Pennsylvania Press.

Whitworth, B., \& Friedman, R. (2009). Reinventing academic publishing online. Part I: Rigor, relevance and practice. First Monday [Online], 14, 8.

About the author:

Alex Gillespie is a lecturer in Social Psychology at the University of Stirling. His main theoretical interest stems from the early American Pragmatist philosophers and psychologists, such as Peirce, Dewey, James and Mead. His empirical research concerns dialogue, intersubjectivity, and the dynamics of trust. He has published a monograph entitled Becoming other: From social interaction to self-reflection and co-edited a volume entitled Trust \& distrust: Sociocultural perspectives.

Email address for correspondence: alex.gillespie@stir.ac.uk 